\title{
Nationwide Stature Estimation from Sitting Height Measurements in Kosovan Adolescents
}

\author{
Estimación de la Estatura a Partir de Mediciones de Altura Sentada en Adolescentes Kosovares
}

\author{
Stevo Popovic
}

POPOVIC, S. Nationwide stature estimation from sitting height measurements in Kosovan adolescents. Int. J. Morphol., 37(2):504$508,2019$.

SUMMARY: The purpose of this research is to determine a regression equation for estimation of stature from sitting height measurements. This research was carried out on 1623 subjects ( 830 male and 793 female) among the population of Kosovan adolescents. The stature and sitting height measurements were taken according to the ISAK protocol, and the data were analyzed statistically; the relationships between stature and sitting height measurements were derived using simple correlation. A comparison of the means of sitting height measurements between sexes was performed using a t-test, while a linear regression analysis was employedto examine the extent to which sitting height measurements can reliably predict stature. The results of this research study confirmed that sitting height reliably predicts stature in both genders of Kosovan adolescents and revealed a very useful finding for physical anthropologists and experts from related fields.

KEY WORDS: Prediction; Anthropometry; Body height; Kosovo.

\section{INTRODUCTION}

Many studies have been conducted confirming that the systematic diagnosis of children's height and the regular measurement of other body proportions can yield beneficial information about children's development (Fredriks et al., 2015). In essence, stature is one of the most important variables when assessing the growth of children and their nutritional status, evaluating the basic energy requirements, adjusting the measures of physical capacity and predicting appropriate drug dosage and setting standards of physiological variables (Mohanty et al., 2001; Golshan et al., 2003, 2007; Datta Banik, 2011; Ter Goon et al., 2011), while one of the most generally known protocols for predicting children's body proportions is to derive the stature/ sitting height ratio and calculate it with reference to age (Fredriks et al.). Moreover, stature cannot always be measured in the typical way, because deformities, such as scoliosis, kyphosis, fractures, amputation et cetera, might disrupt this process (Quanjer et al., 2014). For this reason, relative stature must be calculated from various anthropometric measures that can reliably predict the true stature. The most reliable anthropometric measures that are used as an alternative to estimate true stature are presented in the study published by Bjelica et al. (2012); sitting height was also one of the described anthropometric measures. In contrast, sitting height is also an important measure in many other settings. In addition to the fact that it is a reliable anthropometric measure to accurately estimate stature, it is a proxy for predicting children's body proportions. Sitting height can also be used to predict the statural growth in the cases in which the real stature cannot be measured because of lower limb deformities, such as chondrodystrophic syndromes (Fredriks et al.). The main characteristic of this skeletal syndrome are short limbs, while it is well-known that taller children have longer limbs and vice versa in the general population without the deformities (Yun et al., 1995). Furthermore, it is necessary to highlight that sitting height is gender based and a very good predictor of stature in the elderly (Fatmah, 2010). Therefore, the relationship between stature and sitting height is strongly connected in the previous literature. In the following, the specific characteristics of these measures within the Kosovan population will be presented to justify the necessity of this research study.

In some recent research studies, the recommendations for further investigators have specified that it is essential to find the benefit of using various body indicators in estimating stature in both Kosovan genders (Arifi et al., 2017; Popovic et al., 2017a), largely due to the reason that the Kosovan 
population in both genders had specific body compositions, which is reflected in much more similar body indicators to their western neighbours from Montenegro than to their ethnic compatriots from Albania (J. Jarani, personal communication, 2018). The unusual stature of Montenegrins has long been recognised (the tallest male nation on the planet at the beginning of the 20th century) as well as its distinct body proportions, such as long lower and short upper limbs (Coon, 1975). In contrast, the Kosovan male population has almost reached the average stature of Montenegrins and was almost five centimetres taller than the Albanian male population ( $\mathrm{J}$. Jarani, personal communication, 2018). According to available data, similar estimations are also expected in the female population at the national level (Popovic et al., 2017b; Masanovic, 2017). This might be explained by the fact that Montenegrins and Kosovans live in similar geographic as well as climatic conditions, which are characteristic of the area of the Dinaric Alps. Therefore, these external factors had the dominant influence on the mentioned population growth and special research focused on siting height and its relationship with stature in the Kosovan population is necessary, mostly because many studies with this purpose are available on populations throughout the world, but the available data on Kosovan subjects is very poor, and a national survey is the best solution to determine these unverified facts. Considering the rather sparse recent scientific literature, the purpose of this research was to examine the sitting height in both Kosovan genders and its association with stature.

\section{MATERIAL AND METHOD}

This research included 1623 final year high-school students ( 830 male and 793 female) from Kosovo to be subjects. Two reasons qualified the selected individuals: the first is related to the fact that the growth of an individual ceases by this age, while the second is related to the fact that there is no age-related loss in the stature at this age. The average age of the male subject was $18.26 \pm 0.45$ years old (range 18-20 years), while the average age of the female subject was $18.24 \pm 0.43$ years old (range 1820 years). It is necessary to underscore the fact that the researchers have excluded from the data analysis the individuals with physical deformities as well as those without informed consent. The exclusion criterion was also being non-Kosovan.

The anthropometric measurements, including sitting height and stature, were taken according to the protocol of the International Society for the Advancement of Kinanthropometry (Marfell-Jones et al., 2006). The trained measurers have measured selected anthropometric indicators (same measurer for each indicator), while the quality of their performance was evaluated against the prescribed "ISAK Manual". Finally, the age of each subject was obtained directly from their birth dates.

The analysis was performed using the Statistical Package for Social Sciences (SPSS) version 20.0. Means and standard deviations (SD) were obtained for both anthropometric variables. A comparison of means of sitting height between genders was performed using a t-test. The relationships between stature and sitting height were determined using simple correlation coefficients at a 95 $\%$ confidence interval. Next, a linear regression analysis was carried out to examine the extent to which the sitting height can reliably predict stature. Statistical significance was set at $\mathrm{p}<0.05$.

\section{RESULTS}

A summary of the anthropometric measurements of both genders is shown in Table I. The mean of the stature for males was $179.52 \pm 5.96 \mathrm{~cm}$ and the sitting height was $95.13 \pm 3.56 \mathrm{~cm}$; for females the stature was $165.72 \pm 4.93$ $\mathrm{cm}$, and the sitting height was $90.17 \pm 3.03 \mathrm{~cm}$. The sex difference between sitting height measurements was statistically significant $(t=30.131 ; \mathrm{p}<0.000)$.

In Table II, the simple correlation coefficients and their $95 \%$ confidence interval analysis between the anthropometric measurements are displayed. The associations between stature and sitting height were significant $(\mathrm{p}<0.000)$ and high in this sample, regardless of gender (male: 0.691; female: 0.629).

The results of the linear regression analysis are shown in Table III. The first models were extracted by including age as a covariate. However, it was found that the contribution of age was insignificant; therefore, the age was dropped, and estimations were derived as a univariate analysis. The high values of the regression coefficient (male: 0.691 ; female: 0.629 ) signify that sitting height reliably predicts stature in both Kosovan sexes (male: $\mathrm{t}=27.48, \mathrm{p}<0.000$; female: $\mathrm{t}=22.77, \mathrm{p}<0.000$ ), which confirms the R-square (\%) for males (47.7) as well as for females (39.6).

The associations between sitting height measurements and stature among the above models is displayed in a scatter diagram (Fig. 1). 
Table I. Anthropometric measurements of the study subjects.

\begin{tabular}{|c|c|c|}
\hline Subjects & $\begin{array}{c}\text { Body Height Range } \\
(\text { Mean } \pm \text { SD })\end{array}$ & $\begin{array}{l}\text { Sitting Height Range } \\
(\text { Mean } \pm \text { SD })\end{array}$ \\
\hline Male & $\begin{array}{c}161.4-198.8 \\
(179.52 \pm 5.96)\end{array}$ & $\begin{array}{c}84.4-105.0 \\
(95.13 \pm 3.56)\end{array}$ \\
\hline Female & $\begin{array}{c}153.3-185.0 \\
(165.72 \pm 4.93)\end{array}$ & $\begin{array}{c}80.0-101.9 \\
(90.17 \pm 3.03)\end{array}$ \\
\hline
\end{tabular}

Table II. Correlation between stature and sitting height of the study subjects.

\begin{tabular}{lccc}
\hline Subjects & $\begin{array}{c}\text { Correlation } \\
\text { Coefficient }\end{array}$ & $\begin{array}{c}95 \% \\
\text { confidence } \\
\text { interval }\end{array}$ & $\begin{array}{c}\text { Significance } \\
\text { p-value }\end{array}$ \\
\hline Male & 0.691 & $0.641-0.740$ & $<0.000$ \\
Female & 0.629 & $0.575-0.683$ & $<0.000$ \\
\hline
\end{tabular}

Table III. Results of linear regression analysis where the sitting height predicts the stature.

\begin{tabular}{lccccc}
\hline Subjects & $\begin{array}{c}\text { Regression } \\
\text { Coefficient }\end{array}$ & $\begin{array}{c}\text { Standard Error } \\
(\mathrm{SE})\end{array}$ & $\begin{array}{c}\text { R-square } \\
(\%)\end{array}$ & t-value & p-value \\
\hline Male & 0.691 & 4.313 & 47.7 & 27.48 & 0.000 \\
Female & 0.629 & 3.837 & 39.6 & 22.77 & 0.000 \\
\hline
\end{tabular}

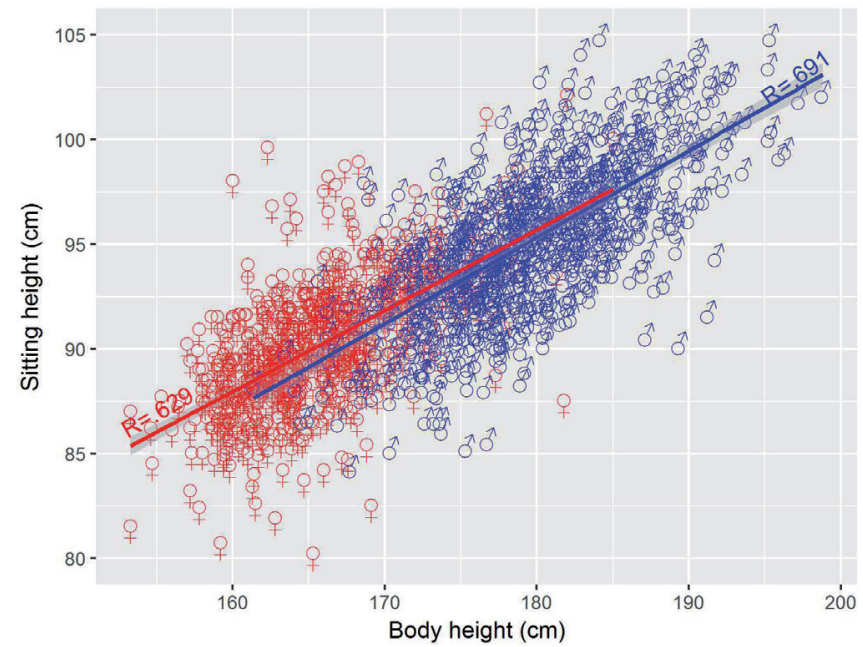

Fig. 1. Scatter diagram and relationship between sitting height measurements and stature among both sexes.

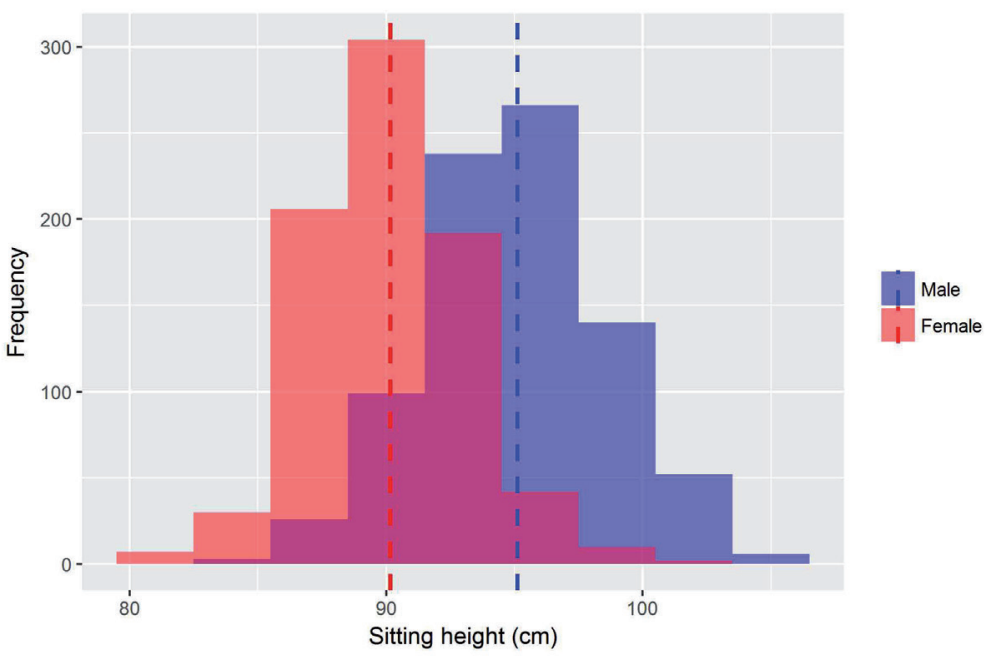

Fig. 2. Frequency of sitting height among both sexes.

\section{DISCUSSION}

Based on different anthropometric parameters, the measurement of stature has been applied and understood since the 19th century in the field of physical anthropology. Many researchers have tried to determine the best anthropometric method for estimating the true stature. According to the accessible literature, it is quite appropriate to use arm span as the most reliable stature predictor (Mohanty et al.). In contrast, it is also confirmed that other anthropometric indicators, including foot length, knee height, tibial length, hand length, vertebral column length, sitting height, length of scapula, etc. can be used as reliable predictors of stature to a certain degree, in those situations in which arm span cannot be provided. Furthermore, it is known that certain anthropometric measurements may vary depending on racial affiliation (Popovic et al., 2016), and from one ethnic group to another (Popovic et al., 2013). It is noteworthy that researches confirming significant differences in previously mentioned anthropometric parameters between ethnically related people who live in different regions, that is, on territories with different geographical characteristics; are more and more common these days. It is therefore impossible to use the results of research obtained in different racial and ethnic groups, different regions, with certain geographical features, and generalize the obtained results, as some other scientific claims propose; however, it is necessary to conduct individual research for each racial and ethnic group, i.e. population living in a geographically specific area for which the requirements that are the subject of this study have not been determined. 
In a study conducted by Fredrix et al. (2015), it was confirmed that sitting height in adolescents reflects $52 \%$ of stature; accordingly, other age groups ( 0 to 21 years) also showed a high relation when sitting height/stature ratio was researched, especially for distinctively short or tall children. In the same study, the authors pointed out that the ratio of sitting height and stature changes from 0.68 in infants to 0.52 in adolescents and found that growth and development in the prepuberty period are manifested more in the extremities than in the length of the trunk. Furthermore, a significant number of studies worldwide (Tanner et al., 1982; Dangour et al., 2002; Bogin et al., 2012), over the course of the past century, confirm the fact that the changes in a positive secular trend are observed more in the growth of the limbs than in the growth of the trunk; however, these findings cannot be confirmed for the population in Kosovo. Therefore, the results of this research will make a significant step forward concerning the anthropometric measures themselves but also those related to the interdependence of sitting height and stature.

The results of this study clearly show the specific anthropometric characteristics of the Kosovan population. Interestingly, the majority of the population in Kosovo is represented by Kosovo Albanians, i.e. Kosovars (92.9\%), while none of the remaining ethnic groups exceed $2 \%$ of the total population: Bosnians (1.6\%), Serbs (1.5\%), Turks (1.1\%), Ashkali (0.9\%), Egyptians (0.7 \%), Gorani (0.6 \%), Roma $(0.5 \%)$, while $0.2 \%$ provided no answer. Therefore, there are no significant ethnic differences in the population living in Kosovo; however, as has already been stated, the body composition differs significantly from the body composition of their compatriots living in Albania, which is particularly reflected in the stature. Namely, the Kosovans are about 5 centimetres taller (men: $179.52 \pm 5.96 \mathrm{~cm}$, women: $165.72 \pm$ $4.93 \mathrm{~cm}$ ) that their compatriots from Albania (J. Jarani, personal communication, 2018), while the average altitude is much more similar to the Montenegrins (Popovic, 2017), their neighbors on the west side, with whom they share mountain chains. It is essential to note that a significant number of authors have described the specific body proportions of the population living on the slopes of the Dinaric Alps, and this particularity of the Kosovans should be, in fact, caused by the same factor.

According to the previously mentioned, the measures of the sitting heights (male: $95.13 \pm 3.56 \mathrm{~cm}$; female: $90.17 \pm 3.03$ $\mathrm{cm}$ ) should be in line with the stated facts (Fig. 2), that is, they should be different from the members of the same ethnic group from other geographic regions, and that they have a different relationship with stature in both genders. Since the main goal of this study was to test the assumptions about whether the facts are true for the Kosovans, the main outcome of this study is that it has been confirmed that the population in Kosovo has specific body proportions. Specifically, a significant correlation between the sitting height with stature in both sexes was confirmed (men: $47.7 \%$, women: $39.6 \%$ ), and it can be stated that sitting height is a reliable indicator for assessing stature in both genders in Kosovans, while the obtained results differ significantly in relation to the coefficient of determination acquired in western populations (Fredriks et al.), while data in Montenegro and Albania are not available for this issue; however, it is expected that they should be most similar to Montenegrins, analogous to other available anthropometric measures mentioned previously.

The results of this study provide a new reference for the Kosovo population and confirm the need for the development of specific models when it comes to assessing stature for both genders in Kosovo. However, the authors of this study emphasize that in further research, the separation of the population of this country into regional samples should be considered and analysed separately, mostly because the geographical features (such as the type of soil in question) that could affect anthropometric measures used in this study, and because it has been shown that the estimation of actual stature with the help of foot length varies from region to region in Kosovo (Popovic et al., 2017b; Masanovic et al., 2018). This concern is based on the fact that the entire area of Kosovo does not lie within the Dinaric Alps, which are characteristic in the specific body proportions of the population living in this area. Therefore, in regions on the slopes of other mountain chains, facts that could be confirmed do not correspond to the overall Kosovo sample. Therefore, there is a reasonable assumption that some subsequent studies could confirm that the sitting height/stature ratio could vary from region to region in Kosovo. In contrast, it is worth pointing out that the limitation of this study can be the structure of the sample that was used, which consisted of final year students from high schools. Specifically, some studies assume that the growth and development of adolescents does not cease at that time (P. Grasgruber, personal communication, 2016; G. Jurak, personal communication, 2017), that is, that even after the age of 18 years, people continue to grow, and this growth is characterized by the extension of the trunk, which can significantly affect the results of this study and its final conclusions. Although the above assumptions remain at the level of theory, they are supported by the fact that the average stature of university students is significantly higher than high school students in some countries: Bosnia and Herzegovina (Grasgruber et al., 2017; Gardasevic et al., 2017), Poland (Wronka \& PawliñskaChmara, 2009) and Hungary (Szöllosi et al., 1998), while in Montenegro these cases (Bjelica et al.; Popovic) have not been confirmed, and it can easily happen that the same case is established with the Kosovo population, given the certain similarities between Montenegrins and Kosovars, or some common specific features in relation to other populations in the region. The obvious limitation of this study is the fact that 
neither of the Kosovan sexes have reached the full genetic potential and that a positive secular trend can significantly change the facts confirmed in this study. Above all, there is still considerable space for environmental factors to affect their further development. For this reason, it is necessary to control the established facts in this study from time to time, since there is a realistic expectation, based on previous experiences with the European sample (Fredriks et al.), that secular changes in statue will occur in the next two or three decades; therefore, all the relations established so far will be disrupted.

POPOVIC, S. Estimación de la estatura a partir de mediciones de altura sentada en adolescentes Kosovares. Int. J. Morphol., 37(2):504-508, 2019.

RESUMEN: El propósito de esta investigación fue determinar una ecuación de regresión para la estimación de la estatura a partir de las medidas de altura sentada. Esta investigación se llevó a cabo en 1623 sujetos (830 hombres y 793 mujeres) en la población de adolescentes Kosovares. Las medidas de estatura y altura sentada se tomaron de acuerdo con el protocolo ISAK, y los datos se analizaron estadísticamente; las relaciones entre la estatura y las medidas de la altura sentada se derivaron utilizando una correlación simple. Se realizó una comparación de las medias de las mediciones de la altura al sentarse entre los sexos utilizando una prueba t, mientras que se empleó un análisis de regresión lineal para examinar hasta que punto las mediciones de la altura sentada pueden predecir la estatura de manera confiable. Los resultados de este estudio de investigación confirmaron que la altura sentada predice de forma confiable la estatura en ambos sexos de adolescentes Kosovares y reveló un hallazgo muy útil para antropólogos físicos y expertos de campos relacionados.

PALABRAS CLAVE: Predicción; Antropometría; Peso corporal; Kosovo.

\section{REFERENCES}

Arifi, F.; Bjelica, D.; Sermaxhaj, S.; Gardasevic, J.; Kezunovic, M. \& Popovic, S. Stature and its estimation utilizing arm span measurements in Kosovan adults: national survey. Int. J. Morphol., 35(3):1161-7, 2017.

Bjelica, D.; Popovic, S.; Kezunovic, M.; Petkovic, J.; Jurak, G. \& Grasgruber, P. Body height and its estimation utilizing arm span measurements in Montenegrin adults. Anthropol. Noteb., 18(2):69-83, 2012.

Bogin, B.; Smith, P.; Orden, A. B.; Varela Silva, M. I. \& Loucky, J. Rapid change in height and body proportions of Maya American children. Am. J. Hum. Biol., 14(6):753-61, 2002.

Coon, C. S. The Race of Europe. Westport, Greenwood Press, 1975. pp.587-95.

Dangour, A. D.; Schilg, S.; Hulse, J. A. \& Cole, T. J. Sitting height and subischial leg length centile curves for boys and girls from Southeast England. Ann. Hum. Biol., 29(3):290-305, 2002.

Datta Banik, S. Arm span as a proxy measure for height and estimation of nutritional status: a study among Dhimals of Darjeeling in West Bengal India. Ann. Hum. Biol., 38(6):728-35, 2011.

Fatmah. Validation of predicted height model based on arm span, knee height and sitting height in Indonesian elderly people. J. Clin. Med. Res., 2(5):67-73, 2010.

Fredriks, A. M.; van Buuren, S.; van Heel, W. J.; Dijkman-Neerincx, R. H.; Verloove-Vanhorick, S. P. \& Wit, J. M. Nationwide age references for sitting height, leg length, and sitting height/height ratio, and their diagnostic value for disproportionate growth disorders. Arch. Dis. Child., 90(8):807-12, 2005.
Gardasevic, J.; Rasidagic, F.; Krivokapic, D.; Corluka, M. \& Bjelica, D. Stature and Its estimation utilizing arm span measurements in male adolescents from Federation of Bosnia and Herzegovina Entity in Bosnia and Herzegovina. Monten. J. Sports Sci. Med., 6(1):37-44, 2017.

Golshan, M.; Amra, B. \& Hoghogi, M. A. Is arm span an accurate measure of height to predict pulmonary function parameters? Monaldi Arch. Chest Dis., 59(3):189-92, 2003.

Golshan, M.; Crapo, R. O.; Amra, B.; Jensen, R. L. \& Golshan, R. Arm span as an independent predictor of pulmonary function parameters: validation and reference values. Respirology, 12(3):361-6, 2007.

Grasgruber, P.; Popovic, S.; Bokuvka, D.; Davidovic, I.; Hrebícková, S.; Ingrová, P.; Potpara, P.; Prce, S. \& Stracárová, N. The mountains of giants: an anthropometric survey of male youths in Bosnia and Herzegovina. R. Soc. Open Sci., 4(4):161054, 2017.

Marfell-Jones, M.; Olds, T.; Stew, A. D. \& Carter, J. E. L. International Standards for Anthropometric Assessment. Potchesfstroom, International Society for the Advancement of Kinanthropometry, 2006.

Masanovic, B. Relationship between arm span measurements and body height in Dinaric Alpes population: a systematic review. J. Anthropol. Sport Phys. Educ., 1(1):33-7, 2017

Masanovic, B.; Gardasevic, J. \& Arifi, F. Relationship between foot length measurements and body height: a prospective regional study among adolescents in eastern region of Kosovo. Sport Mont, 16(1):9-13, 2018.

Mohanty, S. P.; Babu, S. S. \& Nair, N. S. The use of arm span as a predictor of height: A study of South Indian women. J. Orthop. Surg. (Hong Kong), 9(1):19-23, 2001

Popovic, S. Local geographical differences in adult body height in Montenegro. Monten. J. Sports Sci. Med., 6(1):81-7, 2017.

Popovic, S.; Arifi, F. \& Bjelica, D. Standing height and its estimation utilizing foot length measurements in Kosovan adults: national survey. Int. J. Appl. Exerc. Physiol., 6(2):1-7, 2017a.

Popovic, S.; Bjelica, D.; Georgiev, G.; Krivokapic, D. \& Milasinovic, R. Body height and its estimation utilizing arm span measurements in Macedonian adults. Anthropologist, 24(3):737-45, 2016.

Popovic, S.; Bjelica, D.; Molnar, S.; Jaksic, D. \& Akpinar, S. Body height and its estimation utilizing arm span measurements in Serbian adults. Int. J. Morphol., 31(1):271-9, 2013.

Popovic, S.; Gardasevic, J.; Masanovic, B.; Arifi, F. \& Bjelica, D. Standing height and its estimation utilizing foot length measurements in adolescents from western region in Kosovo. Sport Mont, 15(3):3-7, $2017 \mathrm{~b}$.

Quanjer, P. H.; Capderou, A.; Mazicioglu, M. M.; Aggarwal, A. N.; Banik, S. D.; Popovic, S.; Tayie, F. A.; Golshan, M.; Ip, M. S. \& Zelter, M. All-age relationship between arm span and height in different ethnic groups. Eur. Respir. J., 44(4):905-12, 2014.

Szöllosi, E. Secular trend in Debrecen university students (in Hungarian). Anthropol. Közl., 39:43-51, 1998.

Tanner, J. M.; Hayashi, T.; Preece, M. A. \& Cameron, N. Increase in length of leg relative to trunk in Japanese children and adults from 1957 to 1977 : comparison with British and with Japanese Americans. Ann. Hum. Biol., 9(5):411-23, 1982

Ter Goon, D.; Toriola, A. L.; Musa, D. I. \& Akusu, S. The relationship between arm span and stature in Nigerian adults. Kinesiology, 43(1):38-43, 2011

Wronka, I. \& Pawliñska-Chmara, R. Childhood environment and adult height among Polish university students. Coll. Antropol., 33(4):1039-45, 2009.

Yun, D. J.; Yun, D. K.; Chang, Y. Y.; Lim, S. W.; Lee, M. K. \& Kim, S. Y. Correlations among height, leg length and arm span in growing Korean children. Ann. Hum. Biol., 22(5):443-58, 1995.

\section{Corresponding Author:}

Stevo Popovic, Associate Professor

University of Montenegro

Faculty for Sport and Physical Education

Narodne omladine bb, 81400 Niksic

MONTENEGRO

E-mail: stevop@ac.me

Received: 28-09-2018

Accepted: 16-01-2019 